\title{
Assessment of Prevalence and Factors Associated with Malnutrition Among Under-five Children in West Shoa Zone, Oromia Region, Ethiopia
}

\author{
Tsegaye Benti Muse*, Meseret Ifa Wanjo, Elias Teferi Bala, Habtamu Oljira Desta \\ Department of Public Health, Ambo University, Ambo, Ethiopia \\ Email address: \\ tsegaye2016@gmail.com(T. B. Muse),mesol.ifa@gmail.com(M. I. Wanjo), eliasteferi2015@gmail.com(E. T. Bala), \\ oljirah@gmail.com(H. O. Desta) \\ ${ }^{*}$ Corresponding author
}

\section{To cite this article:}

Tsegaye Benti Muse, Meseret Ifa Wanjo, Elias Teferi Bala, Habtamu Oljira Desta. Assessment of Prevalence and Factors Associated with Malnutrition Among Under-five Children in West Shoa Zone, Oromia Region, Ethiopia. American Journal of Health Research.

Vol. 7, No. 5, 2019, pp. 59-66. doi: 10.11648/j.ajhr.20190705.11

Received: July 1, 2019; Accepted: July 23, 2019; Published: August 8, 2019

\begin{abstract}
Malnutrition is a primary cause of child mortality and morbidity in developing countries, particularly during the first 5 years of life. Worldwide, under nutrition contributes to one third of under-five deaths which also plays a significant role as an underlying cause for growth problem in 230 million children and severe wasting in 50 million children. Hence, the aim of this study was to determine the prevalence and factors associated with malnutrition among under-five year children in West Shoa Zone, Ethiopia. Institution based cross-sectional study was conducted on 374 under-five year children. Systematic random sampling was utilized to include study subjects into the study. Data were collected by using pre-tested structured questionnaire. The data were entered into epi data and transferred into SPSS and World Health Organization Anthro software for analysis. In order to identify significant predictors of malnutrition both bivariate and multivariable logistic regression models were used. The prevalence of stunting, underweight and wasting were $40 \%, 24.9 \%$ and $13.8 \%$ respectively. Magnitude of wasting and underweight was higher for female children while stunting was higher for male children. In addition, malnutrition was more prevalent among rural children than urban dwellers. Antenatal care attendance was predictor of wasting whereas place of residence and growth monitoring were found to be predictors of stunting. In conclusion stunting was more prevalent among study subjects and antenatal care attendance, place of residence and growth monitoring were variables that showed significant association with malnutrition. Hence, there is a need to implement nutritional interventions in the study area giving priority to these identified factors.
\end{abstract}

Keywords: Stunting, Under-five Children, West Shoa

\section{Introduction}

Malnutrition involves both under-nutrition and overweight. Childhood under-nutrition incorporates combination of nutritional disorders such as stunting, underweight and wasting. The overconsumption or overweight is nutritional disorder and is used to measure nutritional imbalance [1]. Under nutrition is one of the main causes of under-five children deaths. Worldwide, under nutrition contributes to one third of under-five deaths [2] which also plays a significant role as an underlying cause for growth problem in 230 million children and severe wasting in 50 million children [3].

Worldwide, in 2011, approximately 165 million (26 per cent), 101 million (16 per cent) and 52 million ( 8 per cent) of under five year children were stunted, underweight and wasted respectively. However, the distribution of this problem around the world is not even as more than 90 per cent of stunted and 70 percent of the wasted children in the world live in Sub-Saharan Africa and South Asia. The magnitude of stunting among under-five year children was 36 percent in Sub-Saharan Africa and 27 per cent in South Asia. Although the magnitude of under nutrition is decreasing worldwide, the overall progress is insufficient because 
millions of children are malnourished and still a significant proportion of children remain at risk [4, 5].

According to Dewey, Kathryn and Begum as quoted in UNICEF (United Nations Children's Fund) 2013 report, it is evident that the effects of childhood under nutrition has long term impact on health and welfare of children as it has great impact on future education, income and productivity. School achievement and school performance of children has association with stunting. In addition, the probability of undernourished girls is greater to become undernourished mothers which may increase the likelihood of delivering babies with low birth weight resulting in intergenerational cycle continuation. Young mothers, especially adolescent girls, face more complex problems if they become pregnant before physical and psychological maturity attained. Nutritional deficiencies may be intensified and passed on to children due to too close pregnancies and giving birth to many children [5].

The magnitudes of malnutrition are shocking among at risk groups and children's poor nutritional status remains severe problem in Ethiopia [6]. Studies in Ethiopia revealed that a child under nutrition is still a common problem. For instance, four studies conducted in Bule Hora district, Oromia region, Dollo Ado district, Somali region, Kombolcha district Oromia region and Hawasa zuria district, South Ethiopia indicated magnitudes ranging from 34.4 to 47.6 per cent, 29.1 to 47.7 per cent and 11.2 to 42.3 per cent for stunting, underweight and wasting respectively [7-10]. In Ethiopia, there exits regional variations on prevalence of stunting with lowest rate ( 22 per cent and 23 per cent) in Gambela Regional State and Addis Ababa respectively, and highest rate (46 per cent each) in Tigray and Affar Regional States [6].

It was indicated in Ethiopian Mini Demographic and Health Survey (EMDHS) of 2014 that the health sector has worked more in order to increase good nutrition practices through strategies such as, health education, treatment of extremely malnourished children and provision of maternal and child micronutrient [6]. In spite of the increased effort, the mean rate of stunting remained 40 percent. However, despite higher prevalence of malnutrition among under-five children, there are limited studies that report about risk factors of stunting among under-five children in Ethiopia and none in the study area. Hence, the aim of this study was to determine the prevalence and factors associated with malnutrition among under-five year children in West Shoa Zone.

\section{Methods and Materials}

\subsection{Study Design and Setting}

Institution based cross-sectional study was conducted among outpatient department attending under-five year children from January to February 2015 in West Shoa Zone, Western Ethiopia. The capital city of West Shoa zone is Ambo town which is located about $114 \mathrm{~km}$ away from Addis Ababa. During the data collection, there were three public hospitals and 88 public health centers in West Shoa zone.

\subsection{Sample Size and Sampling Technique}

The sample size was calculated by using a single population proportion formula considering confidence interval (CI) of $95 \%$, proportion of child malnutrition (p) to be 0.33 , [11], and 5\% margin of error (d). Finally, $10 \%$ nonresponse rate was added giving a final sample size of 374 . A systematic random sampling was used using patients' queue as sampling frame for selecting study participants.

\subsection{Data Collection and Quality Control}

Data were collected using structured questionnaire which was adapted by reviewing various literatures. The questionnaire was first prepared in English and then translated to the local language, Afan oromo. In order to consider possible modifications, the questionnaire was pretested on similar population in one of the health centers in West Shoa zone which was not included in the study. Data collectors were given two days training which covered study objectives, a thorough review of the questionnaire, use of survey instruments, interview techniques, and how to take anthropometric measurements in line with predesigned measurement protocol. Close supervision of enumerators was also made during the data collection by the investigators.

\subsection{Anthropometry}

Length of infants aged 0-23 months was measured in a recumbent position to the nearest $0.1 \mathrm{~cm}$ using a board with an upright wooden base and a movable head piece. Height of children 24 months and older was measured in a standing-up position to the nearest $0.1 \mathrm{~cm}$ using a measuring board. Weight of the lightly clothed infants and children was measured to the nearest $10 \mathrm{~g}$ by UNICEF Electronic Scale. Accuracy of all anthropometric measurements was upheld according to the international reference standard. Measurements were carried out carefully to avoid inconsistencies in data or anthropometric measures.

\subsection{Data Management and Analysis}

Data were entered into Epi data 3.1 and transferred to SPSS version 20.0 for analysis. Descriptive analyses were done for each variable in the study by running frequencies. Anthropometric indices were calculated using WHO (World Health Organization) Anthro version 3.2.2. The indices were expressed as standard deviation units from the median values of the National Center for Health Statistics (NCHS) standard reference data of United States children. Children whose height-for-age, weight-for-height and weight-for-age were below minus two standard deviations from the median of the reference population were considered stunted, wasted and underweight respectively. Prevalence of stunting, wasting and underweight were estimated by running frequencies with their $95 \%$ CI estimates. A biviriate analysis was performed to determine the differentials of under-five stunting, underweight and wasting by explanatory variables. For testing the strengths of the associations and their statistical 
significance, odds ratio and $95 \%$ CI were calculated for each independent variable against the dependent variables (stunting, wasting underweight) using binary logistic regression. Secondly, the variables with p-value less than 0.2 in bivariate analysis were subsequently included in multivariate analysis.

\subsection{Ethical Approval}

Permission was obtained from Ethical Clearance Committee of Ambo University, College of Medicine and Health Sciences and letter of permission was written to zonal health office and health facilities. Oral informed consent was obtained from mothers or caregivers of the children included in the study.

Table 1. Demographic and socio-economic status of the parents/caregivers, West Shoa, Oromia Regional State, Ethiopia, 2015.

\begin{tabular}{|c|c|c|c|}
\hline Variable & & Frequency & Percent \\
\hline \multirow{2}{*}{ Maternal age $(\mathrm{n}=352)$} & $15-34$ & 260 & 73.9 \\
\hline & $35-49$ & 92 & 26.1 \\
\hline \multirow{4}{*}{ Marital status } & Single & 6 & 1.7 \\
\hline & Married & 337 & 93.1 \\
\hline & Divorced & 8 & 2.2 \\
\hline & Widowed & 11 & 3.0 \\
\hline \multirow{4}{*}{ Ethnicity } & Oromo & 303 & 87.7 \\
\hline & Amhara & 39 & 10.8 \\
\hline & Tigre & 6 & 1.7 \\
\hline & Others & 14 & 3.9 \\
\hline \multirow{2}{*}{ Residence } & Urban & 174 & 48.1 \\
\hline & Rural & 188 & 51.9 \\
\hline \multirow{3}{*}{ Head of the house hold } & Husband & 337 & 93.1 \\
\hline & Wife & 21 & 5.8 \\
\hline & Others & 4 & 1.1 \\
\hline \multirow{5}{*}{ Occupation of house hold head } & Government employee & 92 & 25.4 \\
\hline & NGO employee & 18 & 5.0 \\
\hline & Farmer & 81 & 50.0 \\
\hline & Merchant & 57 & 15.7 \\
\hline & Others & 14 & 3.9 \\
\hline \multirow{2}{*}{ Farm land } & Yes & 182 & 50.3 \\
\hline & No & 180 & 49.7 \\
\hline \multirow{4}{*}{ Decision making in family } & Husband & 184 & 50.8 \\
\hline & Wife & 16 & 4.4 \\
\hline & Husband \& wife jointly & 159 & 43.9 \\
\hline & Others & 3 & 0.8 \\
\hline \multirow{2}{*}{ Maternal education } & Formal education & 204 & 56.4 \\
\hline & No formal education & 158 & 43.6 \\
\hline \multirow{2}{*}{ Paternal education } & Formal education & 300 & 82.9 \\
\hline & No formal education & 62 & 17.1 \\
\hline \multirow{2}{*}{ Family size } & $2-5$ & 237 & 65.5 \\
\hline & $>5$ & 125 & 34.5 \\
\hline \multirow{2}{*}{ Under 5 year children in $\mathrm{HH}$} & 1 & 337 & 93.1 \\
\hline & $2-3$ & 25 & 6.9 \\
\hline \multirow{2}{*}{ Family income in Birr } & $<500$ & 118 & 32.6 \\
\hline & $>501$ & 244 & 67.4 \\
\hline
\end{tabular}

\subsection{Child Characteristics and Caring Practice}

Out of 362 under-five children observed at outpatient departments, 196 (54.1\%) of them were males. Two hundred twenty one $(61 \%)$ of the children were born in health institutions and the rest were born at home. Most of the children, 297 (82\%), were exclusively breast fed for four to six months (Table 2).

\section{Results}

\subsection{Socio-demographic Characteristics of Parents/Care Givers}

Three hundred seventy four under-five year children with their mothers/caregivers were selected to participate in the study and 362 responded appropriately making a response rate $96.8 \%$. Out of the total children observed at under-five OPDs, $309(85.4 \%)$ of them were brought by their mothers, $36(9.9 \%)$ by their fathers and $17(4.7 \%)$ by others. Majority, $303(83.7 \%)$, of the respondents belong to the Oromo ethnic group and $177(48.9 \%)$ of them were Orthodox Christianity followers (Table 1$)$. 
Table 2. Child characteristics and caring practices, West Shoa, Oromia Regional State, Ethiopia, 2015.

\begin{tabular}{|c|c|c|c|}
\hline Variable & & Frequency & Percent \\
\hline \multicolumn{4}{|l|}{ Child characteristics } \\
\hline \multirow{2}{*}{ Child sex } & Male & 187 & 51.7 \\
\hline & Female & 175 & 48.3 \\
\hline \multirow{2}{*}{ Place of birth } & Home & 141 & 39.0 \\
\hline & Health institution & 221 & 61.0 \\
\hline \multirow{3}{*}{ Birth order } & 1 & 105 & 29.0 \\
\hline & $2-4$ & 201 & 55.5 \\
\hline & $>4$ & 56 & 15.5 \\
\hline \multirow{2}{*}{ Birth interval (in years) } & $<2$ & 255 & 70.4 \\
\hline & $\geq 2$ & 107 & 29.6 \\
\hline \multirow{4}{*}{ Birth weight } & $\geq 2500 \mathrm{gm}$ & 174 & 48.1 \\
\hline & $<2500$ gm & 15 & 4.1 \\
\hline & Not weighed & 123 & 34.0 \\
\hline & Don't remember & 50 & 13.8 \\
\hline \multicolumn{4}{|l|}{ Child care practices } \\
\hline \multirow{3}{*}{ Exclusive breastfeeding } & $<4$ months & 33 & 9.1 \\
\hline & 4-6 months & 302 & 83.4 \\
\hline & $>6$ months & 27 & 7.5 \\
\hline \multirow{2}{*}{ Duration of total breastfeeding } & $\geq 24$ months & 206 & 56.9 \\
\hline & $<24$ months & 156 & 43.1 \\
\hline \multirow{2}{*}{ Immunization } & Ever immunized & 334 & 92.3 \\
\hline & Not immunized & 28 & 7.7 \\
\hline \multirow{2}{*}{ Vitamin A supplementation } & Yes & 246 & 68.0 \\
\hline & No & 116 & 32.0 \\
\hline \multirow{2}{*}{ Seek treatment for sick child } & Yes & 297 & 82.0 \\
\hline & No & 65 & 18.0 \\
\hline
\end{tabular}

\subsection{Maternal and Environmental Conditions}

Age of a mother at first child birth was greater than eighteen for most of them, 231 (65.6\%). Two hundred eighty three (78.2\%) of the mothers had given birth to a maximum of four children. Only18 (5\%) of the households reported pipe water as their source of water, and two hundred ninety (80.1\%) of households dispose waste on open field (Table 3 ).

Table 3. Maternal and Environmental Conditions, West Shoa, Oromia Regional State, Ethiopia, 2015.

\begin{tabular}{|c|c|c|c|}
\hline Variable & & Frequency & Percent \\
\hline \multicolumn{4}{|l|}{ Maternal conditions } \\
\hline \multirow{2}{*}{ Age of mother } & $15-34$ & 260 & 73.9 \\
\hline & $35-49$ & 92 & 26.1 \\
\hline \multirow{2}{*}{ Age at first child birth $(\mathrm{n}=352)$} & $15-18$ & 123 & 34.9 \\
\hline & $>18$ & 229 & 65.1 \\
\hline \multirow{2}{*}{ Total child born to a mother } & $\leq 4$ & 283 & 78.2 \\
\hline & $>4$ & 79 & 21.8 \\
\hline \multirow{2}{*}{ Antenatal care visit } & Yes & 250 & 69.1 \\
\hline & No & 112 & 30.9 \\
\hline \multirow{2}{*}{ Ever using family planning } & Yes & 228 & 63.0 \\
\hline & No & 134 & 37.0 \\
\hline \multirow{2}{*}{ Use of extra food during pregnancy } & Yes & 57 & 15.7 \\
\hline & No & 305 & 84.3 \\
\hline \multicolumn{4}{|l|}{ Environmental conditions } \\
\hline \multirow{6}{*}{ Water source } & River & 36 & 9.9 \\
\hline & Unprotected spring & 66 & 18.2 \\
\hline & Protected spring & 52 & 14.4 \\
\hline & Private well & 36 & 9.9 \\
\hline & Common well & 154 & 42.5 \\
\hline & Pipe water & 18 & 5.0 \\
\hline \multirow{3}{*}{ Per capita water use } & $\leq 10$ liters & 168 & 46.4 \\
\hline & 10-20 liters & 61 & 16.9 \\
\hline & $>20$ liters & 133 & 36.7 \\
\hline \multirow{2}{*}{ Latrine available } & Yes & 240 & 66.3 \\
\hline & No & 122 & 33.7 \\
\hline
\end{tabular}




\begin{tabular}{llll}
\hline Variable & & Frequency & Percent \\
\hline \multirow{2}{*}{ Presence of window } & Yes & 310 & 85.6 \\
& No & 52 & 14.4 \\
& Open field & 290 & 80.1 \\
Waste disposal system (solid and liquid wastes) & Private/Communal pit & 39 & 10.8 \\
& Burn & 26 & 7.2 \\
\hline
\end{tabular}

\subsection{Child Nutritional Status}

$(\mathrm{HAZ}<-2)$ and $90(24.9 \%)$ were under weight $(\mathrm{WAZ}<-2)$.

From the total children observed at under-five OPDs, 50 Out of the total malnourished children, most of them were $(13.8 \%)$ were wasted $(\mathrm{WHZ}<-2), 112(40 \%)$ were stunted

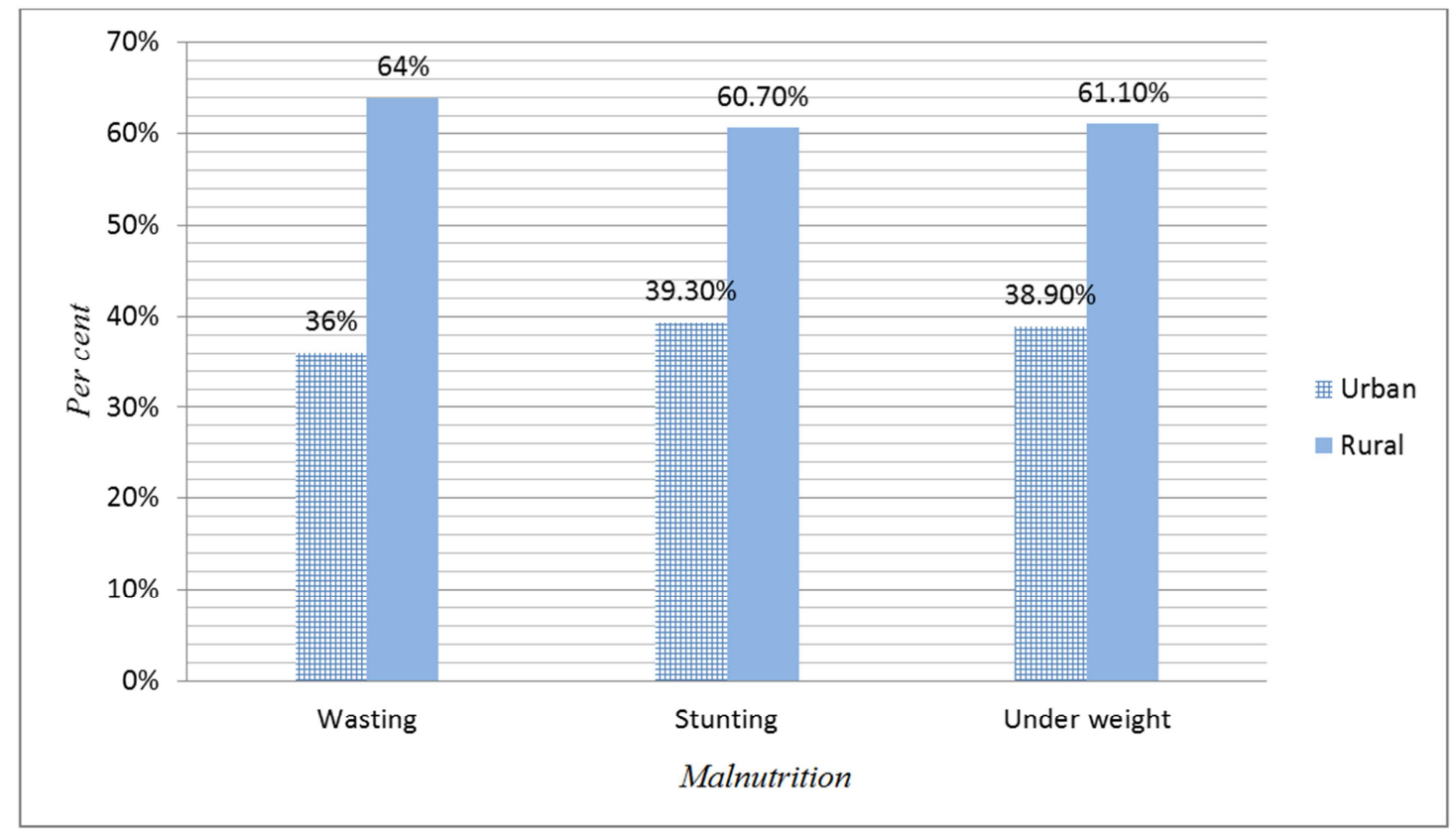

Figure 1. Child malnutrition by residence, West Shoa, Oromia Regional State, Ethiopia, 2015.

\subsection{Analysis of Determinants of Child Malnutrition}

Bivariate and multivariate analysis of the determinants of malnutrition: wasting, stunting and underweight, among under-five year children was performed.

Wasting had significant association with having farm land, attending antenatal care (ANC) and the time at which ANC visit initiated in binary logistic regression analysis. However, in multiple logistic regression analysis, only ANC visit was significantly associated with wasting of children. The likelihood of wasting was 2.1 times higher in children born to mothers who did not attend ANC visit regardless of the number of visit $(\mathrm{AOR}=2.1,95 \% \mathrm{CI}$ : $1-2.5)$ in contrast to children born to mothers who had ANC visit (Table 4).

The result of binary logistic regression showed that place of residence, maternal and paternal education, maternal age, growth monitoring follow up and family size had association with stunting. However, only growth monitoring follow up and place of residence were found to be significantly associated with stunting in multiple logistic regression analysis. Children who did not attend growth monitoring follow up had higher likelihood of stunting (AOR $=3.4,95 \%$ CI: 1.7-6.9) when compared to children who had growth monitoring follow up. The probability of developing stunting $(\mathrm{AOR}=1.4,95 \% \mathrm{CI}: 1.4-2.5)$ was higher among rural children compared to urban children (Table 5).

For underweight, binary logistic regression analysis showed association with residence, maternal education, ANC attendance, treatment seeking when child is sick, child's sex and measles. However, in multiple logistic regression analysis, no variable was found to be significantly associated with underweight.

Table 4. Bivariate and multiple logistic regression analyses of selected correlates of wasting, West Shoa, Oromia Regional State, Ethiopia, 2015.

\begin{tabular}{|c|c|c|c|c|c|}
\hline \multirow{2}{*}{ Variable } & & \multicolumn{2}{|c|}{ Wasting $(n=50)$} & \multirow{2}{*}{ Crude OR (95\% CI) } & \multirow{2}{*}{ Adjusted OR (95\% CI) } \\
\hline & & No & $\%$ & & \\
\hline \multirow{2}{*}{ ANC attendance } & Yes & 22 & 44 & 1.0 & 1.0 \\
\hline & No & 28 & 56 & $1.9(1-3.6)^{*}$ & $2.1(1.0-2.5)^{*}$ \\
\hline
\end{tabular}


Table 5. Bivariate and multiple logistic regression analyses of selected correlates of stunting, West Shoa, Oromia Regional State, Ethiopia, 2015.

\begin{tabular}{|c|c|c|c|c|c|}
\hline \multirow{2}{*}{ Variable } & & \multicolumn{2}{|c|}{ Stunting $(\mathrm{n}=112)$} & \multirow{2}{*}{ Crude OR (95\% CI) } & \multirow{2}{*}{ Adjusted OR (95\% CI) } \\
\hline & & No & $\%$ & & \\
\hline \multirow{2}{*}{ Residence } & Urban & 44 & 39.3 & 1.0 & 1.0 \\
\hline & Rural & 68 & 60.7 & $1.7(1.1-2.6)^{*}$ & $1.4(1.4-2.5)^{*}$ \\
\hline \multirow{2}{*}{ Growth monitoring } & Yes & 61 & 54.5 & 1.0 & 1.0 \\
\hline & No & 51 & 45.5 & $2.2(1.4-3.4)^{*}$ & $3.4(1.7-6.9)^{*}$ \\
\hline
\end{tabular}

\section{Discussion}

The current study tried to identify the prevalence of underfive year children malnutrition and its associated factors. The study showed that the overall prevalence of stunting among study participants was $40 \%$. This finding is similar to a finding of Mini Ethiopian Demographic and Health Survey (EDHS) of 2014. Other studies conducted in Ethiopia show varied magnitude of stunting. For instance, studies conducted in West Gojam, Hidabu Abote District and Shire Indaselassie of Tigray region show $43.2 \%, 47.6 \%$, and $56.6 \%$ respectively. The current finding is slightly similar with the West Gojam case, however, lower than that of Hidabu Abote and Shire Indaselassie [12-14]. The difference may be due to seasonal variation, topography and difference in study period.

On the other hand, studies carried out in Ondo State, Nigeria, Ouagadougou, Burkina Faso and Bagamoyo district hospital in Tanzania show low prevalence of stunting compared to the current study, $12.5 \%, 8.37 \%$ and $8.8 \%$ respectively [15-17]. This variation may be explained in terms of socio-economic difference between the current and previous study area populations and types of food consumed based on cultures of the countries.

The magnitudes of all forms of malnutrition (wasting, stunting and underweight) were highest among rural children than urban children which is consistent with other research findings $[6,15,18,19]$. This is possibly due to dependence of rural community mainly on seasonal agriculture to obtain their food [20].

Place of residence and growth monitoring follow up were the independent predictors of stunting. The likelihood of stunting among children dwelling in rural area was 1.4 times higher than their counterparts. This is similar with several studies $[14,17,21,22]$. In addition, studies reveal that stunting can be prevented through monitoring of child growth by assessing them routinely using 'WHO standard' [23, 24]. This study also showed that the likelihood of stunting in under-five year children who had no routine assessment of growth was 3.4 times than children who had the assessment. Routine assessment of child growth is crucial for detecting inadequacy of nutrients intake by children. It enables on time identification of deviation from normal nutritional status indicating provision of corrective education (intervention) before malnutrition occurs [25].

The prevalence of underweight and wasting at national level was reported to be $9 \%$ and $25 \%$ respectively [6]. The current study showed that the magnitude of underweight was $24.9 \%$, which is similar to the 2014 MEDHS result. However, wasting is $13.8 \%$ which is higher than the national report. This might be due to the fact that the current study subjects were sick children attending under-five outpatient departments in selected health institutions while the EDHS is a national level community based survey. It is also higher $(1.41 \%)$ than finding of a study conducted in Bagamoyo district hospital, Tanzania, which may be as a result of socioeconomic difference [17]. Conversely, the current finding is significantly lower $(64.1 \%)$ than finding from Felegehiwot referral hospital, Bahir Dar [26]. As Felegehiwot is referral hospital, seriously ill children may be referred to the hospital from other health institutions resulting in variation of prevalence of wasting.

The result of multivariate analysis showed that antenatal care is significantly associated with wasting. Children whose mothers did not attend antenatal care service were 2.1 times more probable to face wasting than children whose mothers attended antenatal care service. Other studies show similar finding with the current study [9, 27]. Wasting may be related within appropriate breastfeeding, malpractices in weaning diet and food hygiene during early childhood which could be interceded by educating mothers during antenatal care visit.

\section{Limitation of the Study}

Difficulty to determine potential temporal relationship between malnutrition and various factors due to the study design (cross-sectional) and respondents' recall bias concerning past events like childhood illness history \& breastfeeding patterns were the major limitations. Other limitations might include social desirability bias when responding to questions and information bias resulting from not knowing the precise age of a child and lack of growth monitoring card.

\section{Conclusion and Recommendations}

This study shows that wasting, stunting and underweight are high among under-five children indicating that under-five malnutrition is still an important public health problem in the study area. In addition, all forms of malnutrition were found to be more common among rural children than urban dwellers. Place of residence and growth monitoring were found to be independent predictors of stunting while antenatal care utilization was significantly associated with wasting. The study indicates that there is a need to design effective programs to solve malnutrition in the area taking the identified factors into consideration and giving special attention to children who are at greater risk. It is also essential to deliver appropriate health information. 


\section{Authors' Contributions}

Tsegaye Benti conceived the idea, wrote the proposal and collected data. All of the authors participated in data analysis, drafting the manuscript and finally read and approved the manuscript.

\section{Conflict of Interest}

The authors declare that they have no competing interests.

\section{Acknowledgements}

We are thankful to Ambo University for providing us financial support to conduct this study. We are grateful to West Shoa Health Office, the respective Woreda Health Offices and health institutions. Finally, we acknowledge the study subjects for their participation in the study patiently.

\section{References}

[1] WHO. Nutrition Landscape Information System (NLIS) country profile indicators: interpretation guide. 2010.

[2] You D, New J, Wardlaw T. Levels and trends in child mortality. Report 2012. Estimates developed by the UN Interagency Group for Child Mortality Estimation. 2012.

[3] Eastwood MA. Principles of human nutrition: Springer; 2013.

[4] De Onis M, Brown D, Blossner M, Borghi E. Levels and trends in child malnutrition. UNICEF-WHO-The World Bank joint child malnutrition estimates. 2012.

[5] Nutrition I. The Achievable Imperative for Global Progress New York. NY United Nations Children's Fund: New York, NY, USA. 2013.

[6] Central Statistical Agency. Ethiopia Mini Demographic and Health Survey 2014. Addis Ababa, Ethiopia; 2014.

[7] Asfaw M, Wondaferash M, Taha M, Dube L. Prevalence of undernutrition and associated factors among children aged between six to fifty nine months in Bule Hora district, South Ethiopia. BMC Public health. 2015; 15 (1): 41.

[8] Demissie S, Worku A. Magnitude and factors associated with malnutrition in children 6-59 months of age in pastoral community of Dollo Ado district, Somali region, Ethiopia. Sci J Public Health. 2013; 1 (4): 175-83.

[9] Zewdie T, Abebaw D. Determinants of Child Malnutrition: Empirical Evidence from Kombolcha District of Eastern Hararghe Zone, Ethiopia. Quarterly Journal of International Agriculture. 2013; 52 (892-2016-65185): 357.

[10] Debeko DD, Goshu AT. Nutritional status of under-five children in Hawassa Zuria District, Southern Ethiopia. Am J Health Res. 2015; 3 (5): 286-92.

[11] Mulugeta A, Hagos F, Kruseman G, Linderhof V, Stoecker B, Abraha Z, et al. Child malnutrition in Tigray, northern Ethiopia. East Afr Med J. 2010 Jun; 87 (6): 248-54. PubMed PMID: 23057267. Epub 2010/06/01. eng.

[12] Brhane G, Regassa N. Nutritional status of children under five years of age in Shire Indaselassie, North Ethiopia: Examining the prevalence and risk factors. Kontakt. 2014; 16 (3): e16170 .

[13] Teshome B, Kogi-Makau W, Getahun Z, Taye G. Magnitude and determinants of stunting in children underfive years of age in food surplus region of Ethiopia: the case of west gojam zone. Ethiopian Journal of Health Development. 2009; 23 (2).

[14] Yisak H, Gobena T, Mesfin F. Prevalence and risk factors for under nutrition among children under five at Haramaya district, Eastern Ethiopia. BMC pediatrics. 2015; 15 (1): 212.

[15] Akorede QJ, Abiola OM. Assessment of nutritional status of under five children in Akure South Local Government, Ondo State Nigeria. Int J Res Rev Appl Sci. 2013; 14 (3): 671.

[16] Daboné C, Delisle HF, Receveur O. Poor nutritional status of schoolchildren in urban and peri-urban areas of Ouagadougou (Burkina Faso). Nutrition journal. 2011; 10: 34. PubMed PMID: 21504619. Pubmed Central PMCID: PMC3103411. Epub 2011/04/21. eng.

[17] Juma OA, Enumah ZO, Wheatley H, Rafiq MY, Shekalaghe S, Ali A, et al. Prevalence and assessment of malnutrition among children attending the Reproductive and Child Health clinic at Bagamoyo District Hospital, Tanzania. BMC public health. 2016; 16 (1): 1094.

[18] Singh JP, Gupta SB, Shrotriya VP, Singh PN. Study of nutritional status among under five children attending out patient department at a primary care rural hospital, Bareilly (UP). Sch J App Med Sci. 2013; 1 (6): 769-73.

[19] Kandala N-B, Madungu TP, Emina JB, Nzita KP, Cappuccio FP. Malnutrition among children under the age of five in the Democratic Republic of Congo (DRC): does geographic location matter? BMC public health. 2011; 11 (1): 261.

[20] Baiphethi MN, Jacobs PT. The contribution of subsistence farming to food security in South Africa. Agrekon. 2009; 48 (4): 459-82.

[21] Kavosi E, Hassanzadeh Rostami Z, Kavosi Z, Nasihatkon A, Moghadami M, Heidari M. Prevalence and determinants of under-nutrition among children under six: a cross-sectional survey in Fars province, Iran. International journal of health policy and management. 2014 Jul; 3 (2): 71-6. PubMed PMID: 25114945. Pubmed Central PMCID: PMC4122078. Epub 2014/08/13. eng.

[22] Medhin G, Hanlon C, Dewey M, Alem A, Tesfaye F, Worku $\mathrm{B}$, et al. Prevalence and predictors of undernutrition among infants aged six and twelve months in Butajira, Ethiopia: the P-MaMiE Birth Cohort. BMC Public Health. 2010; 10: 27. PubMed PMID: 20089144. Pubmed Central PMCID: PMC2826285. Epub 2010/01/22. eng.

[23] Uauy R, Kain J, Mericq V, Rojas J, Corvalan C. Nutrition, child growth, and chronic disease prevention. Ann Med. 2008; 40 (1): 11-20. PubMed PMID: 18246473. Epub 2008/02/05. eng.

[24] Sakisaka K, Wakai S, Kuroiwa C, Cuadra Flores L, Kai I, Mercedes Aragon M, et al. Nutritional status and associated factors in children aged 0-23 months in Granada, Nicaragua. Public health. 2006 May; 120 (5): 400-11. PubMed PMID: 16504227. Epub 2006/03/01. eng.

[25] WHO. Programme of Nutrition. WHO Global Database on Child Growth and Malnutrition. 
[26] Lijalem M, Ahmed A, Mulate A, Asmare A, Bahiru K. Severity of malnutrition and treatment responses in under five children in Bahir Dar Felege Hiwot Referral Hospital, Northwest Ethiopia. J Food Nutr Sci. 2014; 2 (3): 93-8.
[27] Siddiqi MN, Haque MN, MA G. Malnutrition of under-five children: evidence from Bangladesh Asian Journal of Medical Sciences. 2011 Sep 17; 2 (2): 113-9. 